Extradición y derechos humanos: algunas reflexiones a partir del caso fujimori

(sentencia dictada por la Corte Suprema con fecha 21 de septiembre de 2007)

Gonzalo Aguilar Cavallo

páginas 423 - 433

\title{
EXTRADICIÓN Y DERECHOS HUMANOS: ALGUNAS REFLEXIONES A PARTIR DEL CASO FUJIMORI (SENTENCIA DICTADA POR LA CORTE SUPREMA CON FECHA 21 DE SEPTIEMBRE DE 2007)
}

Gonzalo Aguilar Cavallo*

\section{Introducción}

Es indudable que la presencia de Fujimori en Chile y la solicitud de extradición presentada por la República del Perú ante la República de Chile, en razón de la imputación de ilícitos penales, algunos de los cuales configuraban hechos constitutivos de crímenes internacionales, generó una serie de expectativas algunas de las cuales fueron satisfechas y otras quedaron pendientes. A continuación revisaremos brevemente las lecciones que es posible extraer a partir del denominado caso Fujimori y, especialmente, de la sentencia dictada por la Corte Suprema de Justicia con fecha 21 de septiembre de 2007.

\section{I.- Inmunidad}

En un caso reciente que han conocido los tribunales nacionales de Chile, el caso Fujimori, los representantes del ex - Presidente sostuvieron como ejes centrales de su defensa que los crímenes que se le imputaban se encontraban prescritos y que éste gozaba de inmunidad de jurisdicción en su condición de ex - Jefe de Estado. La invocación de la inmunidad ha sido una

* Profesor de Derecho Internacional Público y Derechos Humanos de la Universidad de Talca, Doctor en Derecho, MA en Relaciones Internacionales, LLM en Derechos Humanos y Derecho Humanitario. E-mail: gaguilar@utalca.cl. Miembro del Centro de Estudios Constitucionales, Universidad de Talca-Campus Santiago. El autor quiere agradecer la valiosa cooperación y el soporte de Rébecca Steward. Con todo, cualquier error u omisión es exclusivamente del autor. 
de las defensas más utilizadas en el foro interno, respecto de este tipo de casos. En este sentido es importante tener presente los Principios de Nuremberg que, sin duda, han pasado a formar parte del Derecho Internacional general ${ }^{1}$. Así fue afirmado por el Secretario General de la Organización de Naciones Unidas en su informe al Consejo de Seguridad sobre la creación del Tribunal Penal Internacional para la ex - Yugoslavia y este criterio fue confirmado por los Estados al aprobarse el informe sin ningún voto en contra ${ }^{2}$. Del mismo modo, el Tribunal Penal Internacional para la ex - Yugoslavia, en el caso Blaskic, ha reiterado que los Principios de Nuremberg forman parte del Derecho Internacional consuetudinario ${ }^{3}$.

En este sentido, correctamente en nuestra opinión, señala Fuentes que "si esa fuera efectivamente la regla, podríamos decir que un Estado a quien se solicita la entrega de un ex Jefe de Estado no podría excusarse de cumplir el requerimiento"4. Esto es justamente lo que ha ocurrido, aun cuando sin referencia ni aplicación de la normativa del Derecho Internacional Penal, en la sentencia dictada por la Corte Suprema en el caso Fujimori. En efecto, en este caso, en materia de inmunidad, la sentencia reprodujo los argumentos del juez Álvarez, aclarando que "[q]ue la inmunidad de jurisdicción en la forma contemplada en el Convenio de Viena sobre Relaciones Diplomáticas, dice relación con los actos ejecutados por el representante diplomático dentro del país donde se encuentra acreditado, pero naturalmente no se extiende a

Corte I.D.H.: Caso Almonacid Arellano y otros vs. Chile. Excepciones Preliminares, Fondo, Excepciones y Costas. Sentencia de 26 de Septiembre de 2006. Serie C No 154, par. 97, p. 45; Vid. Resolución 95 (I) de la Asamblea General de las Naciones Unidas, de 11 de diciembre de 1946, que confirma los principios de derecho internacional reconocidos por el Estatuto del Tribunal Militar Internacional de Nuremberg y por el fallo de este Tribunal; Vid. Los Principios del Derecho Internacional consagrados por el Estatuto del Tribunal de Nuremberg y por el fallo de este Tribunal, adoptados por la Comisión de Derecho Internacional de las Naciones Unidas, aprobados mediante Resolución 488 (V) de la Asamblea General de las Naciones Unidas, de 12 de diciembre de 1950, «Formulación de los principios de Nuremberg»; Vid. Resoluciones 1074 D (XXXIX) de 28 de julio de 1965 y 1158 (XLI) de 5 de agosto de 1966, relativas al castigo de los criminales de guerra y de las personas que hayan cometido crímenes de lesa humanidad, del Consejo Económico y Social de las Naciones Unidas.

Gutiérrez Posse, Hortensia: "La relación entre el derecho internacional humanitario y los tribunales penales internacionales", en Revista Internacional de la Cruz Roja, núm. 861 (2006), pp. 1-24, especialmente, p. 3; Vid. Informe presentado por el Secretario General de la Organización de las Naciones Unidas de conformidad con el párrafo 2 de la Resolución 808 (1993) del Consejo de Seguridad, doc. S/ 25704, 3 de mayo de 1993, pars. 4144; "La constatación por el Secretario General del carácter consuetudinario de estos instrumentos tiene un alto valor probatorio de su carácter vinculante para todos los Estados conforme al artículo 25 de la Carta de las Naciones Unidas, en la medida en que el Consejo de Seguridad aprobó el Informe del Secretario General sin ninguna reserva". Exposición presentada por la Federación de Asociaciones de Defensa y Promoción de los Derechos Humanos, doc. E/CN.4/1998/NGO/72, par. 6; Vid. Resolución del Consejo de Seguridad de la Organización de las Naciones Unidas que creó el Tribunal Penal Internacional para la ex-Yugoslavia, doc. S/ RES/827 (1993), de 25 de mayo de 1993, pars. 1 y 2.

3 Cfr. The Prosecutor v. Tihomir Blaskic, Case N ${ }^{\circ}$ IT-95-14-T, Judgement, 3-III-2000 y The Prosecutor v. Tihomir Blaskic, Case No IT-95-14-A, Judgement, 29-VII-2004.

4 Fuentes, Ximena: "Las inmunidades de jurisdicción y el Estatuto de la Corte Penal Internacional", en Ius et Praxis, Año 6, núm. 2, 2000, pp. 419-425. 
Extradición y derechos humanos: algunas reflexiones a partir del caso fujimori (sentencia dictada por la Corte Suprema con fecha 21 de septiembre de 2007)

los injustos que pudieren haber cometido en la nación que representa. La indemnidad establecida en dicho tratado debe ser interpretada de acuerdo a su fin y objeto, claramente expuesto en su expresión de motivos, en donde se reconoce, además, que "tales inmunidades y privilegios se conceden, no en beneficio de las personas, sino con el fin de garantizar el desempeño eficaz de las funciones que corresponde llevar a cabo por de las misiones diplomáticas en calidad de representantes de los Estados"5. Como ha quedado de manifiesto, la Corte Suprema adhiere expresamente a la tesis de la improcedencia de la inmunidad cuando de se trata de ilícitos penales, especialmente, si estos ilícitos son constitutivos de crímenes de lesa humanidad.

Este último hecho muestra un progreso en el análisis jurisprudencial y la sentencia de la Corte Suprema en el caso Fujimori constituye un avance más en la dirección correcta, en materia de inmunidad, ya que confirma en forma clara y precisa que, tratándose de crímenes internacionales, los ex - Jefes de Estado o de Gobierno ni ninguna autoridad oficial, goza de inmunidad. En este mismo sentido, con fecha 14 de septiembre de 2007, la Comisión Interamericana de Derechos Humanos, solicitó al Estado de Perú que reabriera la investigación por la masacre del Frontón, lo que incluye proseguir y concluir la investigación del conjunto de los hechos y sancione a los responsables de los mismos -hechos que ocurrieron bajo la presidencia del actual Presidente Alan García Pérez-, y recuerda en este acto, que es inadmisible la invocación de cualquier instituto de derecho interno, entre los que se encuentra la prescripción, que pretenda impedir la investigación y sanción de los responsables de las violaciones graves de los derechos humanos ${ }^{6}$.

\section{II.- Fuentes}

La idea central respecto de la aplicación de las fuentes en materia de extradición ha sido ratificada por la propia Corte Suprema cuando ha señalado que "ante un caso de extradición, si existe un tratado bilateral sobre la materia con el otro Estado, habrá que atenerse a lo que allí se disponga y, en los aspectos no regulados de dicha Convención, si ambos países se hallan adscritos al Código de Derecho Internacional Privado, suscrito el 20 de febrero de 1928 en la Habana, durante la VI Conferencia Internacional Americana y/o a la Convención de Extradición, aprobada en la VII Conferencia Internacional Americana de Montevideo el 26 de diciembre de 1933, se aplicarán sus normas supletoriamente; y a falta de éstas, los principios generales del Derecho Internacional. En ausencia de tratados, cobran vigencia estos principios como mecanismos reguladores de la extradición"7. Exactamente como señala la Corte Suprema en

Corte Suprema de Chile: Caso solicitud de de extradición de Alberto Fujimori, sentencia de fecha 21 de septiembre de 2007, rol 3744-07, p. 2.

C.I.D.H.: Escrito de Observaciones Cumplimiento de Sentencia (Durand y Ugarte vs. Perú), 14 de septiembre de 2007, par. 15 y 20.

Corte Suprema: Caso solicitud de extradición por Argentina de don Marco Antonio Medalla Medalla. Sentencia de fecha 26 de abril de 2005, rol 1579-2005, considerando $4^{\circ}$. 
el fallo señalado, cobran vigencia los principios generales del Derecho Internacional como mecanismos reguladores de la extradición, ya sea que no existen tratados al respecto o que estos tratados no han considerado o previsto la situación de que se trata. Justamente, esto último es, al menos en parte, lo ocurrido con el caso Fujimori, ya que involucraba como capítulos de extradición hechos constitutivos de crímenes internacionales, los cuales no fueron previstos en los tratados de extradición aplicables, por lo que deberían haberse aplicado los principios generales del Derecho Internacional Penal.

La sentencia de primera instancia, al igual que la Sala Penal de la Corte Suprema, ha adoptado una posición sin considerar el Derecho Internacional Penal. Por supuesto, la actitud del primero es más inquietante porque denegó la extradición, mientras que, en el segundo caso, al menos, el tribunal acogió la solicitud de extradición. Resulta evidente que los hechos examinados y respecto de los cuales versan las acusaciones contra el Sr. Fujimori constituyen crímenes internacionales, es decir, graves y serias violaciones a los derechos humanos.

La Corte Interamericana de Derechos Humanos se ha pronunciado a este respecto, al menos, en dos ocasiones, a saber, Barrios Altos y La Cantuta, señalando que se trata de serias y graves violaciones a los derechos humanos y condenando al Estado peruano por lo hechos acaecidos durante el gobierno de Fujimori. Como la Corte Interamericana de Derechos Humanos no es un tribunal internacional de naturaleza penal, no se ha podido pronunciar respecto de la responsabilidad internacional penal de carácter individual de los que han cometido dichos crímenes internacionales, pero, sin lugar a dudas, las sentencias de la Corte constituyen más que un indicio de que ello ha sido así.

El proceso en Chile contra Fujimori se enfocó, en nuestra opinión, equivocadamente desde la perspectiva de la extradición, que, efectivamente, es Derecho Penal Internacional, es decir, es la regulación en materia procesal penal para casos en que el sospechoso de haber cometido crímenes en un Estado determinado se encuentre físicamente en el territorio de otro Estado. Como las peticiones se formulan de poder judicial de un Estado - a través de su Gobierno- al poder judicial de otro Estado, evidentemente, para estos casos, las relaciones entre los Estados se regulan como todas las relaciones entre sujetos de derecho internacional, por tratados, la costumbre o de acuerdo a los principios generales.

Entre Chile y Perú existe el Tratado de Extradición suscrito en Lima el 5 de Noviembre de 1932, cuyo artículo XIII dispone que las leyes del país requerido o de refugio prevalecerán sobre las del país requirente. De acuerdo con esto, en el caso mencionado, rigen las disposiciones del párrafo $2^{\circ}$ "De la extradición pasiva”, del Título VI del Libro III, del Código de Procedimiento Penal Chileno, y específicamente de su artículo 274.

Tal como ha señalado el Ministro Ballestero en su voto disidente al fallo de la Corte Suprema, "[s]e trata de la normativa que soberanamente se han dado ambas naciones, sin 
Extradición y derechos humanos: algunas reflexiones a partir del caso fujimori (sentencia dictada por la Corte Suprema con fecha 21 de septiembre de 2007)

hacer ninguna de ellas reserva de aplicación de otros textos sobre la materia"8. Esto último es totalmente cierto con las siguientes precisiones. Necesariamente, debe considerarse que se trata de un tratado celebrado en la primera mitad del siglo XX, antes de la Segunda Guerra Mundial y que, obviamente, no consideró los crímenes internacionales ni, por supuesto, todo el avance, evolución y progreso que ha experimentado el Derecho Internacional, el Derecho de los derechos humanos, el Derecho Internacional Penal, el Derecho Constitucional y el Derecho Penal, en más de 70 años. En este sentido, para una interpretación de las normas del Tratado deben aplicarse, al menos, los principios de desarrollo progresivo, evolutivo y expansivo.

Además, la Corte Suprema ha utilizado la Convención sobre Extradición suscrita en Montevideo el año 1933 y los artículos 344 a 381 de la Convención sobre Derecho Internacional Privado o Código de Bustamante ${ }^{9}$. Del mismo modo que se ha señalado respecto del Tratado de Extradición entre Chile y Perú, los dos instrumentos internacionales anteriores no han incorporado la perspectiva contemporánea y la evolución experimentada fundamentalmente por los derechos humanos en los últimos 70 años, labor que le corresponde, en este caso, esencialmente, al juez. ¿Cómo es posible resolver una solicitud de extradición aplicando criterios para extradiciones que versan sobre delitos comunes y, sobre todo, normas y principios que emanan de instrumentos internacionales que datan de hace más de medio siglo, pre-segunda guerra mundial?

Esta falta de consideración del Derecho Internacional de los Derechos Humanos y del Derecho Internacional Penal queda en evidencia ya que en el fallo de la Corte Suprema de fecha 21 de septiembre de 2007 sólo se ha hecho referencia a la expresión derechos humanos en 6 ocasiones, sólo en 6 ocasiones en un fallo de más de 200 fojas. La Corte Suprema hace alusión a la Corte Interamericana de Derechos Humanos una sola vez en dicho fallo (a fojas 169), refiriéndose a la sentencia dictada con fecha 14 de marzo de 2001 en el caso Barrios Altos. Esto es algo sintomático y preocupante, toda vez que el caso de la extradición de Alberto Fujimori, contenía hechos de violaciones graves de los derechos humanos que, a su vez, de acuerdo con la jurisprudencia de la propia Corte Interamericana de Derechos Humanos en el caso Barrios Altos y La Cantuta, configuraban crímenes contra la humanidad. Estos dos títulos de incriminación justificaban por sí solos para conceder la extradición o negarla y asumir el juzgamiento del imputado por esos hechos. Por lo tanto, que el fallo de la Corte Suprema no se refiera ni una sola vez al Derecho Internacional Penal y que no mencione ni en una sola

$8 \quad$ Sentencia de la Corte Suprema de Chile, Caso solicitud de de extradición de Alberto Fujimori, de fecha 21 de septiembre de 2007, rol 3744-07, p. 204.

La Convención sobre Derecho Internacional Privado o Código de Bustamante fue adoptada en La Habana, Cuba, en la Sexta Conferencia Internacional Americana, con fecha 20 de febrero de 1928 y ratificada por Chile en 1933, promulgada por Decreto 374 del Ministerio de Relaciones Exteriores con fecha 10 de abril de 1934 y publicada en el Diario Oficial con fecha 25 de abril de 1934. 
oportunidad la expresión crímenes internacionales y que se rija por dos Tratados anteriores a la Segunda Guerra Mundial, sin tomar en consideración el desarrollo normativo que ha alcanzado el Derecho Internacional Penal y el Derecho de los Derechos Humanos, no puede sino arrojar un mal diagnóstico.

\section{III.- Valoración}

En efecto, la interpretación y valoración que se puede hacer del fallo de la Corte Suprema en el caso Fujimori es, por un lado, positiva, en el sentido que se concedió la extradición y eso permitirá juzgar al imputado por los hechos de que se le acusa, pero, por otro lado, surgen puntos que manifiestan inquietud. Uno de los aspectos más relevantes que mueven a reflexión es la absoluta falta de referencia al Derecho Internacional Penal, no obstante que había, al menos, dos capítulos de incriminación constitutivos de crímenes contra la humanidad. En su defecto, la Corte se ha sujetado a la aplicación del Derecho Penal de la extradición tradicional. En este sentido, es conveniente tener presente lo señalado por el juez federal argentino Gabriel Cavallo en el fallo que declaró la nulidad de las leyes de punto final y obediencia debida, cuando afirma que "[...] la magnitud y la extrema gravedad de los hechos que ocurrieron en nuestro país en el período señalado, son lesivos de normas jurídicas que reflejan los valores más fundamentales que la humanidad reconoce como inherentes a todos sus integrantes en tanto personas humanas. En otras palabras, los hechos descriptos tienen el triste privilegio de poder integrar el puñado de conductas señaladas por la ley de las naciones como criminales, con independencia del lugar donde ocurrieron y de la nacionalidad de las víctimas y autores. Tal circunstancia, impone que los hechos deban ser juzgados incorporando a su análisis jurídico aquellas reglas que la comunidad internacional ha elaborado a su respecto, sin las cuales no sería posible valorar los hechos en toda su dimensión. En este sentido, el analizar los hechos exclusivamente desde la perspectiva del Código Penal supondría desconocer o desechar un conjunto de herramientas jurídicas elaboradas por el consenso de las naciones especialmente para casos de extrema gravedad como el presente. Sería un análisis válido pero, sin duda, parcial e insuficiente" 10 .

La preocupación, en este sentido, es doble, tanto en cuanto, además de que el fallo no invoca ni aplica el Derecho Internacional Penal, se dan todas las condiciones que el propio juez Cavallo, en el caso de Argentina, señala en su sentencia, para que en Chile se invoque, se aplique y se cumpla con el Derecho Internacional Penal, con el Derecho Internacional de los derechos humanos y, en general, con el Derecho Internacional. Por su claridad, pero además por su similitud con nuestro país, conviene recordarlas: "[...] las normas del derecho de gentes

\footnotetext{
10 Sentencia del Juez Federal argentino Gabriel Cavallo, Caso "Simón, Julio, Del Cerro, Juan Antonio s/sustracción de menores de 10 años", que anuló las leyes de punto final y de obediencia debida, de fecha 6 de marzo de 2001, en causa No. 8686/2000, Buenos Aires, Argentina, considerando III.
} 
Extradición y derechos humanos: algunas reflexiones a partir del caso fujimori (sentencia dictada por la Corte Suprema con fecha 21 de septiembre de 2007)

son vinculantes para nuestro país y forman parte de su ordenamiento jurídico interno. La propia Constitución Nacional establece el juzgamiento por los tribunales nacionales de los delitos contra el derecho de gentes (art. 118). Por otra parte, como se verá, la República Argentina se ha integrado, desde sus albores, a la comunidad internacional, ha contribuido a la formación del derecho penal internacional y ha reconocido la existencia de un orden supranacional que contiene normas imperativas para el conjunto de las naciones (ius cogens)" "11. Junto con esto, es necesario recordar que es un deber primordial del Estado - a través de todos sus órganos ejecutivo, legislativo y judicial- el respeto y protección, junto con cumplir y hacer cumplir, los derechos humanos. En efecto, como lo ha señalado Silk, "[e]l foco de las acciones de protección de los derechos humanos tiene que ser el Estado, que es quien tiene el deber de respetarlos y protegerlos bajo la Carta de la ONU y bajo el derecho convencional y el consuetudinario. Más importante que la obligación legal es el hecho de que un Estado competente y fuerte puede ser un efectivo protector de derechos"12.

El fallo de la Corte Suprema señala que la extradición debe someterse al principio de que "el sujeto extraditado no puede ser juzgado por una figura delictiva distinta de aquella por la cual se solicita la extradición". El mismo fallo continúa diciendo que este principio "se encuentra consagrado en diversos tratados bilaterales y multilaterales sobre la materia. Así, el Código de Derecho Internacional Privado, conocido como Código de Bustamante, dispone en su artículo 353: "Es necesario que el hecho que motiva la extradición tenga carácter de delito en la legislación del Estado requirente y en la del requerido". Igualmente el artículo I, letra b), del Tratado Multilateral de Extradición de Montevideo de 1933 preceptúa que: "Cada uno de los Estados signatarios se obliga a entregar, de acuerdo con las estipulaciones de la presente Convención, a cualquiera de los otros Estados que los requiera, a los individuos que se hallen en su territorio y estén acusados o hayan sido sentenciados, siempre que concurran las circunstancias siguientes: b) Que el hecho por el cual se reclama la extradición tenga el carácter de delito y sea punible por las leyes del Estado requirente y por las del Estado requerido con la pena mínima de un año de privación de libertad"13.

Siempre, la reflexión aquí, de acuerdo a este principio de doble incriminación, es que el hecho por el cual se solicita la extradición sea punible en ambos Estados, requirente y requerido, lo cual, evidentemente, ignora la regulación que de los crímenes internacionales hace el Derecho

11 Sentencia del Juez Federal argentino Gabriel Cavallo, Caso "Simón, Julio, Del Cerro, Juan Antonio s/sustracción de menores de 10 años", que anuló las leyes de punto final y de obediencia debida, de fecha 6 de marzo de 2001, en causa No. 8686/2000, Buenos Aires, Argentina, considerando III.

12 Silk, James: "La justicia penal internacional y la protección de los derechos humanos: ¿el Estado de derecho o la arrogancia del derecho?", en Saba, Roberto (Ed.): Los derechos fundamentales, Ediciones del Puerto, Buenos Aires, 2003, pp. 277-290, especialmente, p. 283.

13 Sentencia de la Corte Suprema de Chile, Caso solicitud de de extradición de Alberto Fujimori, de fecha 21 de septiembre de 2007, rol 3744-07, considerando sexto, p. 8. 
Internacional. Esto último debiera inducir a preguntarse por qué el sentenciador ha obrado de esta manera, sobre todo teniendo en consideración que la propia legislación nacional, a través del artículo $647 \mathrm{~N}^{\circ} 2^{\circ}$, del Código de Procedimiento Penal, en cuanto ordena que la investigación que exige la extradición pasiva se contraerá especialmente: “ $2^{\circ}$.- A establecer si el delito que se le imputa es de aquellos que autorizan la extradición según los tratados vigentes o, a falta de éstos, en conformidad a los principios del Derecho Internacional", señala que en último término, hay que sujetarse a los principios de Derecho Internacional, y uno de estos principios es que estando en presencia de un hecho que puede configurar un crimen internacional el Estado del foro debe aplicar el Derecho Internacional Penal y, por tanto, aplicar la regla aut dedere aut iudicare, es decir, o lo extradita o lo juzga, pero no hay refugio para el responsable de crímenes internacionales.

\section{IV.- Sumisión al Derecho Internacional}

En nuestra opinión, un paso en la dirección correcta, se encuentra representado por la afirmación expresa de la sumisión al Derecho Internacional que en materia de extradición efectúa el fallo de la Corte Suprema. En efecto, la Corte Suprema señala en su considerando duodécimo que las reglas sobre cómputo de los plazos de prescripción "se condice[n] con la sumisión al derecho internacional que, en esta materia, acepta el ordenamiento positivo chileno en los artículos $647 \mathrm{~N}^{\circ} 2^{\circ}$, y 651 del Código de Procedimiento Penal, con la idea que la extradición es un trámite basado en el derecho internacional de asistencia jurídica entre los Estados y bajo reglas de tratados internacionales. Se logra esta cooperación en la medida que se cumplan las regulaciones normativas que éstos han aceptado, a fin de evitar que un delito quede sin sanción por la fuga del responsable del ilícito"14.

Confirma esta alusión expresa a las reglas y principios de Derecho Internacional, la referencia que el sentenciador hace a la Convención de Viena sobre Derechos de los Tratados de 1969 y al principio trascendental de la buena $\mathrm{fe}^{15}$. En efecto, la Corte señala en su fallo que "además, debe tenerse presente que de acuerdo a lo establecido en el artículo 31, inciso primero, de la Convención de Viena sobre el Derecho de los Tratados - la que ha sido ratificada tanto por Chile como por el Perú-, "un Tratado deberá interpretarse de buena fe conforme al sentido que haya de atribuirles a los términos del Tratado teniendo en cuenta su objeto y fin", inteligencia que debe estar iluminada por el principio fundamental de la buena fe, que obliga a las partes a aplicar el tratado de forma razonable, de modo tal que su fin pueda ser logrado y del que deriva

\footnotetext{
14 Sentencia de la Corte Suprema de Chile, Caso solicitud de de extradición de Alberto Fujimori, de fecha 21 de septiembre de 2007, rol 3744-07, considerando duodécimo, p. 11

15 La Convención de Viena sobre el Derecho de los Tratados fue ratificada por Chile el 9 de abril de 1981, promulgada por Decreto Supremo N³81, del mismo año, publicado en el Diario Oficial de 2 de junio de 1981.

16 Sentencia de la Corte Suprema de Chile, Caso solicitud de de extradición de Alberto Fujimori, de fecha 21 de septiembre de 2007, rol 3744-07, considerando duodécimo, p. 11.
} 
Extradición y derechos humanos: algunas reflexiones a partir del caso fujimori (sentencia dictada por la Corte Suprema con fecha 21 de septiembre de 2007)

el dogma de la eficacia, esto es, cuando una disposición de la convención se presta a dos interpretaciones, una de las cuales permite darle efectos y la otra no, debe preferirse la primera"16. En esta afirmación, la Corte Suprema ha confirmado la vigencia y aplicación de tres principios cardinales en materia de Derecho Internacional y, en particular, en materia de Derecho de los Derechos Humanos, a saber, el principio de buena fe, el principio de razonabilidad o coherencia y el principio del efecto útil. En este sentido, la Corte Suprema coincide con lo señalado por la Corte I.D.H. en relación con el deber de cooperación interestatal y la necesidad de erradicación de la impunidad, en cuanto al principio cardinal de la buena fe. En efecto, en el caso Goiburú, la Corte I.D.H. señaló que "el mecanismo de garantía colectiva establecido bajo la Convención Americana, en conjunto con las obligaciones internacionales regionales y universales en la materia, vinculan a los Estados de la región a colaborar de buena fe en ese sentido, ya sea mediante la extradición o el juzgamiento en su territorio de los responsables de los hechos"17. Con esta última expresión, la Corte I.D.H. aprovechó para aludir aunque sea implícitamente al principio aut dedere aut iudicare cuando estemos frente a hechos constitutivos de crímenes internacionales.

Especialmente valiosa para los efectos de la aplicación del Derecho Internacional resultan las referencias explícitas a las obligaciones que para el Estado -órganos legislativos, administrativos y judiciales- emanan de los principios de Derecho Internacional. En efecto, en el caso Fujimori la Corte Suprema señala que "reducir la aplicación del artículo 100 del Código Penal al derecho interno, como pretende la defensa del extraditable, dándole vigencia sólo en el campo de las extradiciones activas y no en las pasivas, importa negar principios básicos del derecho internacional, como son el de entera igualdad de todos los Estados soberanos y el de reciprocidad de las relaciones entre naciones, derivada de esa propia igualdad, principio que, por cierto, encuentra expresa consagración en el preámbulo del Tratado de Extradición de 1932 suscrito entre Chile y Perú"18. Por supuesto, sin dejar de apreciar la importancia de este expreso reconocimiento, es un lugar común sostener que el principio de soberanía y de reciprocidad se encuentran intensamente matizados en el Derecho Internacional contemporáneo, especialmente, en materia de Derecho Internacional de los Derechos Humanos, Derecho Internacional de los Refugiados, Derecho Internacional Humanitario, Derecho Internacional Penal y Derecho Internacional del Medio Ambiente.

Finalmente, el caso Fujimori representa un avance importante en el reconocimiento de ciertos principios elementales en materia de aplicación y sistematización razonable y coherente

17 Corte I.D.H.: Caso Goiburú y otros vs. Paraguay. Sentencia sobre Fondo, Reparaciones y Costas. Sentencia de 22 de septiembre de 2006. Serie C N 153 , par. 131, p. 79.

18 Sentencia de la Corte Suprema de Chile, Caso solicitud de de extradición de Alberto Fujimori, de fecha 21 de septiembre de 2007, rol 3744-07, considerando undécimo, p. 10.

19 Sentencia de la Corte Suprema de Chile, Caso solicitud de de extradición de Alberto Fujimori, de fecha 21 de septiembre de 2007, rol 3744-07, considerando décimo tercero, p. 12. 
del Derecho Internacional y del derecho interno. En efecto, en dicho fallo, la Corte Suprema hace expresa referencia al principio de la compatibilización maximizadora entre ambas normativas, cuando señala que "si bien es cierto el tribunal a quien se pide la extradición de un individuo debiera considerar y observar las condiciones que se establecen en el derecho interno, dicha labor deberá efectuarse conciliando estas últimas disposiciones con las que de manera especial y preferente se han impuesto en los instrumentos internacionales sobre la materia, de tal manera que privilegiando el principio de auxilio mutuo entre las naciones para la conservación de un orden jurídico, se asegure el juzgamiento de todo hecho ilícito y, por consiguiente, se impida su impunidad por la fuga del delincuente" ${ }^{19}$. Esta última afirmación es coincidente con las enseñanzas de la Corte I.D.H. en el caso La Cantuta, cuando observa que "en función de la efectividad del mecanismo de garantía colectiva establecido bajo la Convención, los Estados Partes en la Convención deben colaborar entre sí para erradicar la impunidad de las violaciones cometidas en este caso mediante el juzgamiento y, en su caso, sanción de sus responsables" ${ }^{20}$. En esta línea, la misma Corte I.D.H. ha reafirmado, en el caso mencionado, la vinculación entre el deber de evitar la impunidad y el deber de cooperar entre los Estados, cuando ha señalado que "[a]nte la naturaleza y gravedad de los hechos, más aún tratándose de un contexto de violación sistemática de derechos humanos, la necesidad de erradicar la impunidad se presenta ante la comunidad internacional como un deber de cooperación interestatal para estos efectos" Entre la normativa que regula y orienta a los Estados en este deber de cooperación en materia de crímenes internacionales se encuentran los Principios de cooperación internacional en la identificación, detención, extradición y castigo de los culpables de crímenes de guerra, o de crímenes de lesa humanidad, destacando, para estos efectos, el principio $5^{\circ}$ que señala que "[1] as personas contra las que existan pruebas de culpabilidad en la comisión de crímenes de guerra y crímenes de lesa humanidad serán enjuiciadas y, en caso de ser declaradas culpables, castigadas, por lo general en los países donde se hayan cometido esos crímenes. A este respecto, los Estados cooperarán entre sí en todo lo relativo a la extradición de esas personas"22.

\section{Conclusión}

El fallo de fecha 21 de septiembre de 2007 en el denominado caso Fujimori ha tenido un aspecto positivo y un aspecto negativo. La parte positiva del fallo dice relación con una

\footnotetext{
20 Corte I.D.H.: Caso La Cantuta vs. Perú. Sentencia sobre fondo, reparaciones y costas. Sentencia de 29 de noviembre de 2006. Serie C No 162, par. 227, p. 108.

21 Corte I.D.H.: Caso La Cantuta vs. Perú. Sentencia sobre fondo, reparaciones y costas. Sentencia de 29 de noviembre de 2006. Serie C No 162, par. 160, p. 85.

22 Vid. Principios de cooperación internacional en la identificación, detención, extradición y castigo de los culpables de crímenes de guerra, o de crímenes de lesa humanidad, aprobados por Resolución 3074 (XXVIII) de la Asamblea General, de 3 de diciembre de 1973.
} 
Extradición y derechos humanos: algunas reflexiones a partir del caso fujimori

(sentencia dictada por la Corte Suprema con fecha 21 de septiembre de 2007)

consideración fáctica y una consideración jurídica. La consideración fáctica es que se concedió efectivamente la extradición de Alberto Fujimori al Estado de Perú. La consideración jurídica es que, a pesar de no contener aplicación ni referencias al Derecho Internacional Penal, el fallo ratifica y confirma la aplicación plena en el orden interno de una serie de principios cardinales en materia de Derecho Internacional. La parte negativa, que siembra una sombra de duda e inquietud es la nula referencia a los principios de Derecho Internacional Penal. Lamentablemente, nuestros órganos jurisdiccionales dejaron pasar una oportunidad interesante para desarrollar ciertos principios fundamentales del Derecho Internacional Penal y su plena vigencia en el Derecho interno, lo que nos habría catapultado, en esta materia, a los primeros lugares de los países más avanzados en esta materia. Con todo, desde ya es destacable que esta sentencia marque el primer caso en que un tribunal nacional concede la extradición de un ex Jefe de Estado acusado, inter alia, de cometer crímenes de lesa humanidad. 